\title{
Analisis Kebutuhan Bahan Ajar Video Berbasis Pen Tablet Dalam Pembelajaran Topik Integral Selama Pandemi Covid-19
}

\author{
Nia Maharani* \\ STMIK STIKOM Indonesia, Denpasar Bali 80225 \\ *Email: maharani.nst@gmail.com \\ DOI: https://doi.org/10.33369/pendipa.6.1.41-48
}

\begin{abstract}
[Analysis of the need for pen tablet-based video teaching materials in learning integral during the Covid-19 pandemic]. Educators need innovation in teaching and learning activities in order to achieve the desired goals. In this case, the role of technology has a big role. Various breakthroughs were made by utilizing technology. Educators must use technology to increase the learning opportunities of their students by choosing or making mathematical tasks that take advantage of what technology can be done efficiently and well. Calculus is one of the basic mathematics courses which is very important for students to master. As a basic subject, calculus is closely related to other subjects. One of the important topics in calculus is integrals. Integral calculus studies the material of integrals, starting from the definition, types of integrals and rules on integrals and integral applications. The results of research by Suparnadi and Hartono] show that integral calculus is still considered a difficult subject for students. From the results of the preliminary test, it showed that the students' mastery of these subjects was still low, namely $16.7 \%$ of students who obtained grades $A$ and $B$, while the rest were grades $C$ and $E$ [3]. This is also not much different from the condition of students in the Department of Computer Systems STMIK STIKOM Indonesia where from the data the author has, based on previous integral learning that the level of mastery of integral material is still low, namely 69\%.From the description above, a breakthrough is needed in providing teaching materials with online learning conditions during the Covid -19 pandemic and adapting where contemporary students are more easily adapted to technological advances. The breakthrough is to improve mastery of integral material by implementing a technology-based learning using pen tablet-based teaching videos. By paying attention to the needs based on the literature study that has been done, it is also necessary to conduct a needs analysis based on the users of teaching materials, namely students. Therefore, the purpose of this study was to see the need for video teaching materials for pen tablet-based integral material in 86 students of the STMIK STIKOM Indonesia Computer Systems Department in semester 2 as a sample. This type of research is research and development which refers to the $4 D$ theory of development (define, design, development and dissemination) but is limited to the define stage. Data were collected in the form of a questionnaire containing 10 questions. The results of the research indicate that alternative teaching materials other than books or modules that are integrated with technology are needed, namely teaching videos.
\end{abstract}

Keywords: Needs analysis, teaching videos, pen tablet, integrals.

\begin{abstract}
ABSTRAK
Sejak Covid -19 melanda semua sektor terkena dampaknya termasuk sektor pendidikan. Para tenaga pendidik memerlukan inovasi dalam kegiatan belajar mengajar agar tetap tercapai sasaran yang diinginkan. Dalam hal ini peran teknologi memiliki andil besar. Berbagai terobosan dilakukan dengan memanfaatkan teknologi. Tenaga pendidik harus menggunakan teknologi untuk meningkatkan kesempatan belajar peserta didik mereka dengan memilih atau membuat tugas matematika yang memanfatkan teknologi apa yang dapat dilakukan secara efisien dan baik.
\end{abstract}


Kalkulus adalah salah satu matakuliah dasar matematika yang sangat penting untuk dikuasai mahasiswa. Sebagai mata kuliah dasar, kalkulus memiliki kaitan yang erat dengan mata kuliah lainnya. Salah satu topik penting dalam kalkulus adalah integral. Kalkulus integral mempelajari materi integral, mulai dari definisi, jenis-jenis integral dan aturan-aturan pada integral dan aplikasi integral. Hasil penelitian dari Suparwadi (2015) menunjukkan bahwa kalkulus integral masih dianggap sebagai mata kuliah yang sulit bagi mahasiswa. Dari hasil uji pendahuluan yang menunjukkan bahwa penguasaan mahasiswa terhadap mata kuliah tersebut masih rendah, yaitu 16,7 \% mahasiswa yang memperoleh nilai A dan B , sedangkan sisanya adalah nilai C dan D. Hal ini juga tidak jauh berbeda dengan kondisi mahasiswa di Jurusan Sistem Komputer STMIK STIKOM Indonesia dimana dari data penulis miliki, berdasarkan pembelajaran integral sebelumnya bahwa tingkat penguasaan materi integral masih rendah yaitu $69 \%$. Dari uraian di atas maka diperlukan suatu terobosan dalam pemberian materi ajar dengan kondisi belajar daring selama pandemi Covid -19 dan mengadaptasi dimana mahasiswa kekinian lebih mudah beradaptasi dengan kemajuan teknologi. Terobosan tersebut adalah untuk meningkatkan penguasaan materi integral dengan cara menerapkan suatu pembelajaran berbasis teknologi yaitu menggunakan video ajar berbasis pen tablet. Dengan memperhatikan kebutuhan berdasarkan studi literatur yang telah dilakukan perlu dilakukan pula analisis kebutuhan berdasarkan pengguna bahan ajar yaitu mahasiswa. Oleh karena itu tujuan penelitian ini adalah untuk melihat kebutuhan bahan ajar video materi integral berbasis pen tablet pada 86 orang mahasiswa Jurusan Sistem Komputer STMIK STIKOM Indonesia semester 2 sebagai sampel. Adapun jenis penelitian ini adalah penelitian pengembangan (Research and Development) yang merujuk pada teori pengembangan 4D (define, design, development and dissemination) tapi dibatasi hanya pada tahap define. Data dikumpulkan dalam bentuk kuisioner yang berisi 10 pertanyaan. Dari hasil penelitian menunjukkan diperlukan bahan ajar alternatif selain buku atau modul yang terintegrasi dengan teknologi yaitu video ajar.

Kata kunci: Analisis kebutuhan, video ajar, pen tablet, integral.

\section{PENDAHULUAN}

Latar Belakang Masalah

Sejak Covid -19 melanda semua sektor terkena dampaknya termasuk sektor pendidikan. Para tenaga pendidik memerlukan inovasi dalam kegiatan belajar mengajar agar tetap tercapai sasaran yang diinginkan. Dalam hal ini peran teknologi memiliki andil besar. Berbagai terobosan dilakukan dengan memanfaatkan teknologi. Tenaga pendidik harus menggunakan teknologi untuk meningkatkan kesempatan belajar peserta didik mereka dengan memilih atau membuat tugas matematika yang memanfatkan teknologi apa yang dapat dilakukan secara efisien dan baik. Kalkulus adalah salah satu matakuliah dasar matematika yang sangat penting untuk dikuasai mahasiswa. Sebagai mata kuliah dasar, kalkulus memiliki kaitan yang erat dengan mata kuliah lainnya. Salah satu topik penting dalam kalkulus adalah integral. Kalkulus integral mempelajari materi integral, mulai dari definisi, jenis-jenis integral dan aturan-aturan pada integral dan aplikasi integral. Adapun hasil penelitian dan menunjukkan bahwa kalkulus integral masih dianggap sebagai mata kuliah yang sulit bagi mahasiswa (Suparwadi, 2017). Dari hasil uji pendahuluan yang menunjukkan bahwa penguasaan mahasiswa terhadap mata kuliah tersebut masih rendah, yaitu 16,7 \% mahasiswa yang memperoleh nilai A dan B , sedangkan sisanya adalah nilai $\mathrm{C}$ dan $\mathrm{E}$ (Hartono \& Noto, 2017). Hal ini juga tidak jauh berbeda dengan kondisi mahasiswa di 
Jurusan Sistem Komputer STMIK STIKOM Indonesia dimana dari data penulis miliki, berdasarkan pembelajaran integral sebelumnya bahwa tingkat penguasaan materi integral masih rendah yaitu $69 \%$.

Dari uraian di atas maka diperlukan suatu terobosan dalam pemberian materi ajar dengan kondisi belajar daring selama pandemi Covid -19 dan mengadaptasi dimana mahasiswa kekinian lebih mudah beradaptasi dengan kemajuan teknologi. Terobosan tersebut adalah untuk meningkatkan penguasaan materi integral dengan cara menerapkan suatu pembelajaran berbasis teknologi yaitu menggunakan video ajar berbasis pen tablet. Pen tablet merupakan input komputer yang memungkinkan pengguna untuk menggambar dan menulis. Disamping itu penggunaan video ajar berbasis pen tablet membuat mahasiswa tidak merasa jenuh selama perkuliahan daring jika bahan ajar hanya bersumber pada dokumen tertulis dalam bentuk PPT MS. Word maupun PDF.

\section{Rumusan Masalah}

Rumusan masalah dalam penelitian ini yaitu: Bagaimanakah kebutuhan video ajar dalam pembelajaran topik integral selama pandemi Covid-19?

\section{Kajian Teoritik}

Revolusi Industri 4.0 ditambah adanya pandemi Covid -19 mengharuskan para pelaku pendidikan lebih kreatif dan inovatif dalam melaksanakan pendidikan agar sasaran pendidikan dapat terwujud. Berbagai cara ditempuh dalam memberikan bahan ajar kepada para mahasiswa. Pembelajaran dengan sistem daring menuntut kesiapan tenaga pendidik untuk memiliki integrasi dengan teknologi. Tenaga pendidik harus menggunakan teknologi untuk meningkatkan kesempatan belajar peserta didik mereka dengan memilih atau membuat tugas matematika yang memanfaatkan teknologi apa yang dapat dilakukan secara efisien dan baik (Shermann, 2104).
Penelitian baru-baru ini dilakukan tahun 2021 dengan judul "Pengembangan Video Pembelajaran Berbantuan Geogebra Untuk Meningkatkan Kemandirian Belajar Siswa" yang telah terbit pada jurnal Cendikia dengan hasil video pembelajaran berbantuan geogebra efektif digunakan sebagai media atau alat bantu siswa dalam melakukan pembelajaran matematika yang mampu meningkatkan kemandirian belajar siswa (Citra \& Ayu, 2021). Pada tahun 2020 dengan judul "Pengembangan Video Pembelajaran Kalkulus Difrensial Berbasis Pen Tablet" yang terbit pada Jurnal Cendekia dengan hasil penelitian menunjukkan video pembelajaran diferensial dinyatakan valid dengan kriteria sangat baik, praktis dan efektif (Marfi, et.al, 2020). Selanjutnya penelitian yang masih berkaitan dengan video ajar adalah "Pengaruh Penggunaan Video Pembelajaran Terhadap Hasil Belajar Komputer 1 Mahasiswa Pendidikan Matematika Semester II TP.2019/2020 Universitas Pasir Pengaraian tahun 2020 pada Jurnal BSIS dengan hasil ada pengaruh penggunaan video pembelajaran tehadap hasil belajar Komputer 1 mahasiswa program studi pendidikan matematika semester 2 Universitas Pangarai (Arcat, 2020).

Pada tahun 2019 penelitian dan telah publish pada Jurnal Matematika dan Pendidikan Matematika.dengan judul "Analisis Kebutuhan Bahan Ajar Video Berbasis Pen Tablet Dalam Pembelajaran Kalkulus Integral". Menggunakan teori pengembangan 4D yang dibatasi pada tahap define dengan subjek adalah 17 mahasiswa yang telah mengambil mata kuliah kalkulus integral. Data dikumpulkan dalam bentuk wawancara dan penyebaran kuisioner dan dianalisis melalui presentase jawaban mahasiswa. Hasil penelitian menunjukkan diperlukan bahan ajar selain buku/modul ajar yang sebaiknya terintegrasi dengan teknologi yaitu video ajar. Pengembangan video ajar yang baik yaitu menampilkan masalah 
kontekstual, memuat contoh-contoh soal dan penyelesaian dan lebih banyak menampilkan materi pelajaran yang disampaikan dibandingkan tutor/pengajar (Ratri \& Najmi, 2019). Di tahun yang sama dilakukan penelitian berjudul "Pengembangan Video Pembelajaran Materi Integral Pada Pembelajaran Flipped Classroom yang telah terbit pada AKSIOMA Jurnal Ilmiah Pendidikan Matematika dengan hasil video yang dikembangkan memenuhi kriteria valid, praktis dan efektif dan mahasiswa terbantu untuk memahami materi pelajaran dan dapat mengulang-ngulang materi jika lupa (Ario, 2019).

Bahan ajar merupakan alat utama yang harus dipersiapkan oleh pengajar dalam proses pembelajaran. Bahan ajar dapat memiliki banyak bentuk seperti lembar kerja bagi mahasiswa, dalam bentuk poin-poin slide presentasi, buku, video ajar dan lainlain. Penelitian lain yang telah dilakukan pada tahun 2016 dengan judul “ Pengaruh Penggunaan Video Pembelajaran Terhadap Peningkatan Hasil Belajar Mapel IPA di MIN Kroya Cirebon pada jurnal Al Ibtida dengan hasil bahwa video ajar dapat membuat proses belajar dan mengajar jadi lebih efektif dan pemahaman siswa pada Mapel IPA meningkat (Busyaeri, et.al, 2016). Selanjutnya penelitian berjudul "Profil Penguasaan Materi Matematika Sekolah Mahasiswa Pendidikan Matematika Semester VI" tahun 2017 pada jurnal AKSIOMA menghasilkan pembelajaran dengan menggunakan video ajar bisa efektif (Ario, 2017).

Selanjutnya penelitian yang dilakukan tahun 2017 dan terbit pada Jurnal Nasional Pendidikan Matematika dengan judul "Pengembangan Modul Berbasis Penemuan Terbimbing Untuk Meningkatkan Kemampuan Matematis pada Perkuliahan Kalkulus Integral menghasilkan peningkatan kemampuan matematis mahasiswa dengan gabungan teknologi modul berbasis IT.
(Hartomo \& Noto, 2017). Penelitian lain yang memanfaatkan konsep teknologi adalah "Pengaruh Penggunaan Bahan Ajar Mengintegrasikan MSTBK Berbasis ICT" pada tahun 2016 pada Prosiding SEMIRATA dengan hasil video ajar telah terbukti bahwa pembelajaran berjalan efektif dan adanya peningkatan nilai rata-rata untuk mata pelajaran Fisika kelas XI SMA (Akmam, et, al, 2016).

Penelitian dengan judul "Peran Teknologi Video Dalam Flipped Classroom yang terbit pada jurnal Dinamika Teknologi dengan hasil video yang dibuat disukai mahasiswa dan mahasiswa mau mempelajarinya sehingga diperoleh nilai optimal (Chandra \& Nugroho, 2016).

\section{Tujuan Penelitian}

Adapun tujuan penelitian ini adalah tujuan penelitian ini adalah untuk melihat kebutuhan bahan ajar video materi integral berbasis pen tablet pada 86 orang mahasiswa jurusan Sistem Komputer.

\section{METODE PENELITIAN}

\section{Waktu dan Lokasi Penelitian}

Waktu penelitian berlangsung dari bulan April sampai Mei 2021 di jurusan Sistem Komputer STMIK STIKOM Indonesia.

\section{Rancangan Penelitian}

Jenis penelitian ini adalah penelitian pengembangan (Research and Development) dengan mengacu pada model pengembangan 4D yaitu define, design, development and dissemination. Tahap define dikonsentrasikan pada analisis kebutuhan (need assessment) sedangkan tahap selanjutnya dikonsentrasikan pada pengembangan dan implementasi. Adapun metode pelaksanaan penelitian ini adalah yang pertama sekali adalah tahap define. Tahap ini penulis melakukan analisis kebutuhan untuk menentukan masalah dan solusi yang sesuai untuk meningkatkan kompetensi mahasiswa dalam topik integral. Teknik Pengumpulan Data 
Metoda pengumpulan data dilakukan melalui penyebaran kuisioner tertutup secara daring. Instrumen penelitian berupa kuisioner yang terdiri dari 10 pertanyaan dimana mahasiswa menjawab masingmasing pertanyaan dengan memilih Sangat Setuju (SS), Setuju (S), Netral, Tidak Setuju (TS), dan Sangat Tidak Setuju (STS). Selanjutnya yaitu analisis data dengan cara menghitung presentase jawaban mahasiswa pada setiap butir pertanyaan dan mendeskripsikannya.

\section{Metode Analisis Data}

Secara umum data dianalisis secara deskriptif kualitatif yang didukung data kuantitatif untuk memperoleh gambaran tentang kebutuhan bahan ajar video berbasis pen tablet pada topik integral selama pandemi Covid-19.

\section{HASIL DAN PEMBAHASAN}

Butir pernyataan-pernyataan ini disusun untuk mengetahui gambaran tentang kebutuhan ajar video selama pandemi Covid-19 berbasis pen tablet. Pernyataan -pernyataan tersebut berkaitan dengan topik integral, bahan ajar, video ajar dan pen tablet. Pada pernyataan pertama mahasiswa diminta untuk menannggapi bahwa kalkulus merupakan topik yang penting dengan hasil 71,3 $\%$ memberikan tanggapan setuju dan 12,6\% memberikan tanggapan sangat setuju seperti ditunjukkan pada gambar 1. Sedangkan pada pernyataan kedua mahasiswa diminta untuk menanggapi pernyataan bahwa topik integral merupakan topik yang sulit (Suparwadi, 2015) dengan hasil 51,7 \% menyatakan setuju dan 12,6 $\%$ menyatakan tidak setuju.

Pernyataan berikutnya diberikan untuk mengidentifikasi sumber bahan ajar integral. Pernyatan 3 dan 4 dapat dilihat pada gambar 2. Pada pernyataan tiga, mahasiswa menyatakan tidak setuju sebanyak 40,2 \% bahwa bahan ajar integral cukup dari buku ajar, modul dalam bentuk PPT, PDF dan Word.

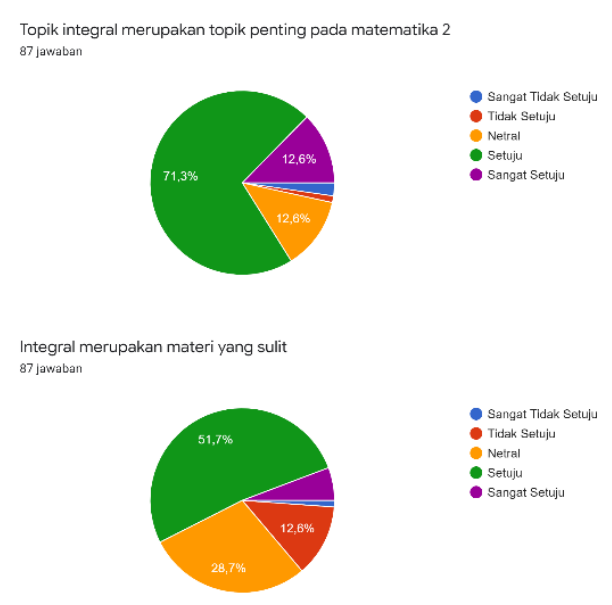

Gambar 1. Hasil pertanyaan kuisioner 1 -2

Pada butir permyataan empat sebanyak $47,1 \%$ memberikan tanggapan sangat setuju serta 43,7 $\%$ mahasiswa menanggapi seuju bahwa butuh alat bantu ajar lain topik integral selama pandemi Covid-19.

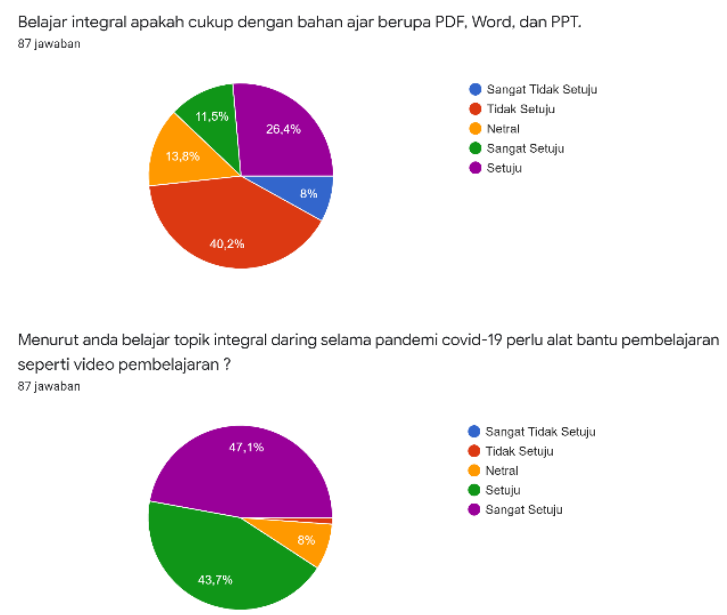

Gambar 2. Hasil pertanyaan kuisioner 3 - 4

Hal ini menunjukkan bahwa butuh alternatif lain sebagai sumber belajar yang menunjang proses pembelajaran integral yang digunakan selama pandemi Covid-19. Duffy dan Jonassen menyatakan bahwa upaya pemecahan masalah dalam pembelajaran dilakukan dengan memanfaatkan berbagai sumber belajar (Isharyadi \& Annajmi, 2019). Seels \& Richey menyatakan bahwa bentuk sumber belajar tidak terbatas pada bentuk cetak seperti buku teks atau modul tetapi terdapat sumber bahan ajar lain menggunakan teknologi seperti video ajar, 
powerpoint interaktif dan lain-lain. Selain itu segala potensi yang dapat dijadikan sumber belajar dalam rangka mendapatkan hasil belajar yang maksimal.

Pernyataan selanjutnya berkaitan dengan penggunaan video ajar dan sebanyak 48,3\% mahasiswa menanggapi setuju dan 42,5\% mahasiswa memberikan tanggapan setuju seperti tampak pada gambar 3. Hal ini menunjukkan bahwa pembelajaran yang terintegrasi dengan teknologi lebih menarik bagi mahasiswa sehingga diharapkan pembelajaran menjadi lebih efektif, efisien dan bervariasi sehingga tidak membosankan. Disamping itu juga sumber bahan ajar yang terintegrasi dengan teknologi bisa diakses dengan mudah oleh mahasiswa di internet untuk memperkaya informasi. Hal ini menunjukkan bahwa internet merupakan kebutuhan dasar mahasiswa selama pandemi. Mahasiswa memberikan tanggapan 65, $5 \%$ setuju dan $18,4 \%$ setuju untuk pernyataan tersebut.

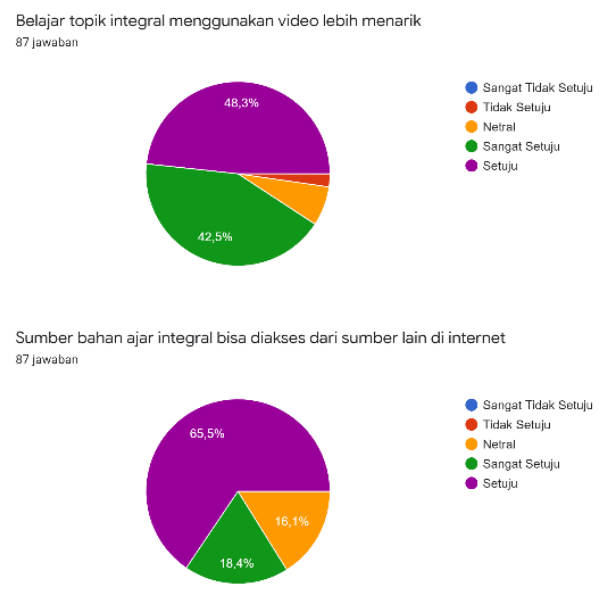

Gambar 3. Hasil pertanyaan kuisioner 5-6

Gambar 4 menunjukkan hasil kuisinoer mahasiswa berkenaan dengan pernyataan bahwa bila bahan ajar berupa video ajar sebaiknya berisi materi singkat beserta contoh dan penyelesaian secara konsep dasar dan sebanyak 43,7 \% menyatakan setuju dan sangat setuju dengan pernyataan tersebut. Pembelajaran matematika selama pandemi harus diramu dalam bentuk konsep-konsep dasar dan contoh kasus agar lebih mudah dipahami. Pernyataan selanjutnya berkaitan dengan bagaimana video ajar ditampilkan seperti butir pernyataan 8 , yaitu tampilan video pembelajaran sebaiknya lebih fokus pada apa yang ditulis oleh tutor daripada wajah dosen pengajar. Pernyataan ini dibuat untuk melihat pilihan kecenderungan mahasiswa dalam melihat berbagai tipe video ajar. Hasilnya $46 \%$ mahasiswa menanggapi setuju, netral 26,4 $\%$ dan $23 \%$ persen sangat setuju. Tampilan bahan ajar juga menentukan respon pengguna bahan ajar. Semakin meanrik tampilannya, maka semakin ingin orang untuk melihatnya. Dalam video ajar, ada video yang menampilkan pengajar atau tutornya, namun adapula yang hanya menampilkan sesuatu yang ditulis oleh pengajarnya. Bila dikaitkan dengan dengan cara membuat video yang lebih berfokus pada tulisan pengajar, salah satu cara yang dapat digunakan adalah pen tablet. Penggunaan pen tablet dalam pembuatan video ajar dapat dikombinasikan dengan video screen (Isharyadi \& Annajmi, 2019).

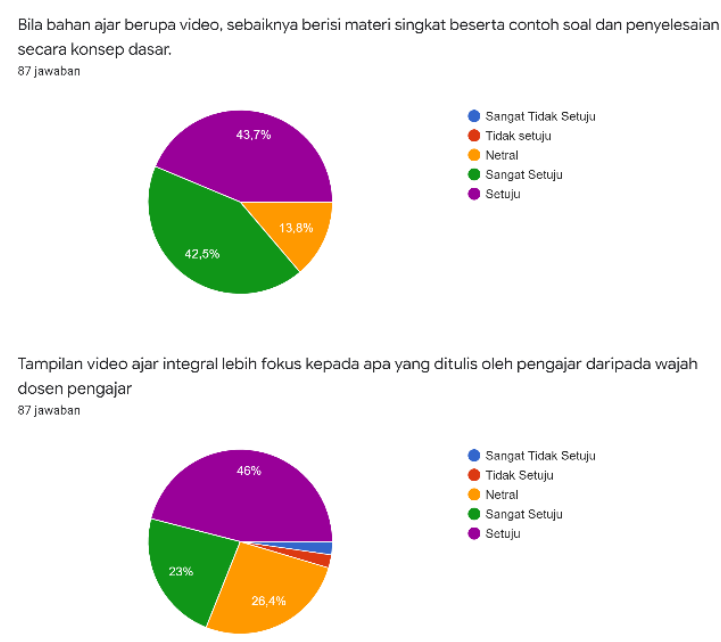

Gambar 4. Hasil pertanyaan kuisioner $7-8$.

Pada pernyataan video ajar merupakan sumber belajar yang efektif, terdapat $49,4 \%$ menyatakan setuju dan 37,9 \% menanggapi setuju. Hal ini menunjukkan bahwa potensi video ajar menjadi altenatif sumber belajar yang efektif. Hal senada juga diungkapkan oleh Purwanti (2015) bahwa memanfaatkan beberapa indera, pelajar akan lebih mudah memahami dan mengingat materi pembelajaran yang menggunakan video dapat menghemat waktu hingga $40 \%$ dan dapat meningkatkan retensi dari $14 \%$ menjadi $38 \%$ (Purwanti, 2015). 


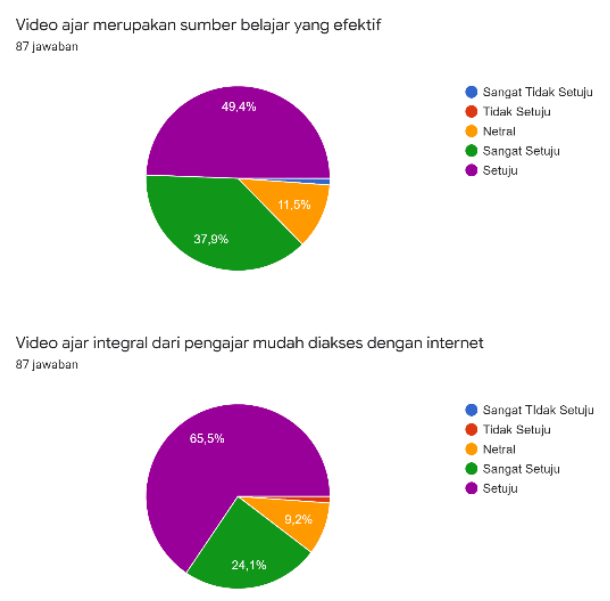

Gambar 5. Hasil pertanyaan kuisioner 9 - 10. Pada era digital dan di masa pandemi ini, pembelajaran sebaiknya dapat diakses dimana saja, baik bahan ajar berupa tulisan maupun video. Akses yang mudah dan cakupan yang luas dapat digunakan melalui internet. Pernyataan terakhir digunakan untuk mengidentifkasi hal tersebut. Hasilnya diperoleh $65,5 \%$ mahasiswa menanggapi setuju dan 24,1 \% mahasiswa menyatakan sangat setuju dan sisanya adalah tanggapan netral. Saat ini internet meruapakan kebutuhan primer bagi banyak kalangan. Sumber belajar bisa disajikan lewat internet, akan memudahkan pelajar untuk mengaksesnya. Mereka dapat mengakses dimana saja dan kapan saja tidak terbatas waktu dan tempat. Analisis kebutuhan (need assessment) yang dilakukan dalam penelitian bertujuan untuk meneliti kebutuhan dari suatu bahan ajar dalam mata kuliah matematika 2 topik integral. Berdasarkan kumpulan informasi yang didapat dari hasil observasi, angket diketahui bahwa bahan ajar yang dibutuhkan mahasiswa adalah video. Dengan perkuliahan online selama pandemi menggunakan internet maka video ajar yang dimaksud adalah video yang terkoneksi dan dapat diakses dengan internet. Video ajar berdasarkan penelitian yang telah dilakukan (Akmam, Amir \& Asrizal, 2016) merupakan bahan ajar yang praktis dan efektif digunakan dalam pembelajaran.

Berdasarkan tanggapan mahasiswa, video ajar sebaiknya lebih banyak menampilkan materi yang diajarkan, dibandingkan dengan tampilan wajah dosennya. Hal ini dapat dilakukan dengan menyediakan video ajar berupa video screen. Hal ini dapat dilakukan dengan menghubungkan hardware berupa papan grafis/pen tablet yang digunakan sebagai pengganti papan tulis. Pen tablet menggunakan teknologi yang menggabungkan fitur terbaik dari tradisional misalnya papan tulis dan modern misalnya slide elektronik sebagai alat pengajaran. Saat ini pen tablet sudah mulai digunakan dalam pembelajaran. Bila digabungkan dengan kanvas digital sebagai media menulis di komputer dan direkam menggunakan video screen akan memungkinkan menghasilkan video yang baik, karena dapat diputar ulang sesuai kebutuhan.

\section{KESIMPULAN}

Berdasarkan hasil kuisioner yang diberikan ke mahasiswa dan hasil observasi peneliti yang juga sebagai dosen pengampu matematika 2, diperoleh kesimpulan bahwa dibutuhkan bahan ajar alternatif lain selain buku ajar, modul atau rangkuman dalam bentuk PPT, PDF dan MS Word yang terintegrasi dengan teknologi selama pandemi Covid-19 karena sistem belajar tidak tatap muka langsung. Video ajar merupakan bahan alternatif yang baik yang digunakan. Pengembangan video ajar yang baik menurut mahasiswa adalah yang berisi materi singkat beserta contoh soal dan penyelesaian secara konsep karena dapat membantu mahasiswa dalam menyelesaikan kasus integral.

Video ajar lebih menampilkan materi daripada wajah pengajar menjadikan mahasiswa menjadi lebih fokus terhadap materi yang disampaikan hal ini dapat dilakukan dengan menggunakan pen tablet. Video ajar sebaiknya dapat diakses dengan mudah menggunakan internet, dengan adanya video ajar maka mahasiswa dapat mengulang materi ajar dengan mandiri apabila masih ada bagian-bagian yang belum dipahami.

\section{UCAPAN TERIMA KASIH}

Penelitian ini terlaksana atas bantuan hibah dari Lembaga Penelitian dan Pengabdian Kepada Masyarakat (LPPM) STMIK STIKOM Indonesia melalui skema Penelitian Dosen Mahasiswa 
(PDM). Peneliti mengucapkan terima kasih atas bantuan tersebut sehingga penelitian yang direncanakan dapat terlaksana dengan baik.

\section{DAFTAR PUSTAKA}

Akmam, Amir, H., \& Asrizal. (2016). Pengaruh Penggunaan Bahan Ajar Mengintegrasikan MSTBK Berbasis ICT Dalam Pembelajaran Fisika DI Kelas XI SMA. Prosiding SEMIRATA, 910-918.

Arcat, (2020). Pengaruh Penggunaan Video Pembelajaran Terhadap Hasil Belajar Komputer 1 Mahasiswa Pendidikan Matematika Pendidikan Matematika Semester II TP.2019/2020 Universitas Pasir Pangarai. Jurnal BSIS, 3(1).

Ario, M. (2019). Pengembangan Video Pembelajaran Materi Integral Pada Pembelajaran Flipped Classroom. AKSIOMA : Jurnal Pendidikan Matematika dan Matematika, 1(2), 72-77

Ario, M. (2017). Profil Penguasaan Materi Matematika Sekolah Mahasiswa Pendidikan Matematika Semester VI. AKSIOMA : Jurnal Program Studi Matematika, 6(3).

Busyaeri, A., Udin, T., \& Zaenuddin. (2016). Pengaruh Penggunaan Video Pembelajaran Terhadap Peningkatan Hasil Belajar Mapel IPA Di MIN Kroya Cirebon. In Pengaruh Penggunaan Video Al Ibtida Vol 3.

Chandra, F., \& Nugroho, Y., W. (2016). Peran Teknologi Dalam Flipped Classroom. Dinamika Teknologi, 8(1), 15-20.
Citra, N., \& Ayu, T. (2021). Pengembangan Vieo Pembelajaran Berbantuan Geogebra Untuk Meningkatkan Kemandirian Belajar Siswa. Cendikia : Jurnal Pendidikan Matematika, 5(1).

Hartono, W., \& Noto,, S.M. (2017). Pengembangan Modul Berbasis Penemuan Terbimbing Untuk Meningkatkan Kemampuan Matematis Pada Perkuliahan Kalkulus Integral. Jurnal Nasional Pendidikan Matematika, 1(2), 320-333.

Marfi, A., Annajmi, A., \& dan Ratri, I. (2020). Pengembangan Video Pembelajaran Kalkulus Diferensial Berbasis Pen Tablet. Cendikia : Jurnal Pendidikan Matematika. 4(2).

Purwanti, B. (2015). Pengembangan Media Video Pembelajaran Matematika dengan Model Assure. Jurnal Kebijakan Dan Pengembangan Pendidikan, 3(1), 42-47.

Ratri, I., \& dan Annajmi. (2019). Analisis Kebutuhan Bahan Ajar Video Berbasis Pen Tablet Dalam Pembelajaran Kalkulus Integral. Jurnal Matematika dan Pendidikan Matematika, 4(1) Maret 2019, 61-72.

Shermann. M. (2014). The Role of Technology in Supporting Students Mathematical thinking : Extending the Metaphors of Amplifier and Reorganizer. Contemprary Issues in Technology and Teacher Education, 14(3), 220-246.

Suparwadi, L. (2015). Peningkatan Kualitas Pembelajaran Kalkulus Integral Melalui Kegiatan Lesson Study Di Program Studi Pendidikan Matematika. Jurnal Pendidikan Matematika, 9 (1) Januari 2015, 35-48. 